\title{
Headache in patients with systemic lupus erythematosus: characteristics, brain MRI patterns, and impact
}

\author{
Gehan Elolemy ${ }^{12^{*}}$ (D), Abdulrahman Al Rashidi ${ }^{2}$, Doaa Youssry ${ }^{3,4}$, Haytham Elziat ${ }^{5}$ and Eman Baraka ${ }^{1}$
}

\begin{abstract}
Background: The prevalence of primary headache in patients with systemic lupus erythematosus (SLE) varies widely and whether it should be attributed to neurological involvement is controversial. We aimed to investigate the prevalence and characteristics of headache in SLE patients, describe its association with disease-related variables and brain imaging, and explore its impact on life.

Results: The overall prevalence of headache was $54.4 \%$, and migraine was the most common type among headache sufferers (48.4\%). Headache severity (VAS) and impact (HIT-6) correlated with SLEDAI-2K $(P=0.019$ and $P$ $<0.001$, respectively) as well as with each other $(P=0.006)$. Brain imaging abnormalities were found in $25.8 \%$, with white-matter hyperintensities (WMH) being the most frequent pathology. Musculoskeletal manifestations, positive anti-phospholipid (aPL) antibodies, and SLEDAI score $\geq 13.5$ were identified as predictors of headache.

Conclusion: Primary headache, especially migraine, is a common feature of patients with SLE, and its presence is associated with negative impact on quality of life. Musculoskeletal features, aPL positivity, and overall disease activity appear to predict primary headache in SLE.
\end{abstract}

Keywords: Systemic lupus erythematosus, Neuropsychiatric lupus, Headache, Impact, Magnetic resonance imaging

\section{Background}

Systemic lupus erythematosus (SLE) is a chronic multisystem autoimmune disease, which affects the central and peripheral nervous system in up to $30 \%$ of cases $[1,2]$. Neuropsychiatric SLE (NPSLE) includes a wide range of heterogeneous neurologic and psychiatric manifestations that reflect variable pathogenetic mechanisms [3, 4].

The relationship between SLE and headache was heavily discussed, but the results were controversial [5]. Although some studies have reported increased headache prevalence in SLE patients [6], others have not found an

\footnotetext{
* Correspondence: Gelolemy@gmail.com; g.olemy@yahoo.com

${ }^{1}$ Rheumatology and Rehabilitation Department, Benha Faculty of Medicine, Benha, Egypt

${ }^{2}$ Rheumatology Unit, Internal Medicine Department, Al Adan Hospital, Al Ahmadi, Kuwait

Full list of author information is available at the end of the article
}

increase in the headache frequency compared to the controls [7].

Various types of primary headaches, especially migraine and tension-type headache (TTH), are commonly recognized as neurological manifestations of SLE [8]. However, secondary causes of headache should be excluded, such as cerebral vasculitis, cerebral venous sinus thrombosis, posterior reversible encephalopathy syndrome, subarachnoid hemorrhage, and meningitis [9].

The term 'lupus headache' is defined as a severe persistent headache, may be migrainous, that does not respond to narcotic analgesia [10]. This type of headache has been considered as a component of the disease spectrum and was categorized as one of 19 neuropsychiatric syndromes in the American college of rheumatology (ACR) criteria for NPSLE [11]. Although lupus headache has a strong weight in the SLE disease activity index (SLEDAI-2K) suggesting the presence of an

\section{Springer Open}

(c) The Author(s). 2021 Open Access This article is licensed under a Creative Commons Attribution 4.0 International License, which permits use, sharing, adaptation, distribution and reproduction in any medium or format, as long as you give appropriate credit to the original author(s) and the source, provide a link to the Creative Commons licence, and indicate if changes were made. The images or other third party material in this article are included in the article's Creative Commons licence, unless indicated otherwise in a credit line to the material. If material is not included in the article's Creative Commons licence and your intended use is not permitted by statutory regulation or exceeds the permitted use, you will need to obtain permission directly from the copyright holder. To view a copy of this licence, visit http://creativecommons.org/licenses/by/4.0/. 
underlying significant pathology, its clinical significance remains unclear. This issue raises the inquiry; is it a symptom of morbidity related to acute pain but has no other significance or is it a sign of significant underlying pathology [12]?

Primary headaches may provide an evidence for silent neurological involvement in SLE [13]. Several modalities have been used for evaluating NPSLE, and brain magnetic resonance imaging (MRI) remains the most common imaging procedure utilized in clinical practice [14]. Furthermore, brain MRI is an important non-invasive technique that proved superiority in detecting the presence and evolution of cerebral pathology in SLE patients with neuropsychiatric manifestations [15].

Therefore, we aimed to investigate the prevalence and characteristics of headache in SLE patients, describe its association with disease-related variables and brain imaging, and explore its impact on life.

\section{Methods}

\section{Study design and patients}

A total of 57 SLE patients, aged between 18 and 59 years, participated in this cross-sectional comparative study. Patients were evaluated consecutively, and finally, the headache sufferers were compared with the nonheadache sufferers. The study complied with the Helsinki Declaration and was approved by the institute's ethical committee. All participants gave their informed written consent to be included in the study.

The diagnosis of SLE was established based on the presence of at least four of ACR 1982 revised criteria for SLE classification $[16,17]$. Patients with neuropsychiatric events not attributed to SLE such as a previous history of epilepsy, electrolyte imbalance, or drug side effects were excluded. Patients with a history of headache prior to the diagnosis of SLE were also excluded. Moreover, exclusion criteria included the presence of antiphospholipid syndrome or other concomitant systemic autoimmune diseases.

\section{Assessment of lupus-related variables}

Demographic variables were collected, such as age, gender, and drug history. A complete history was obtained, and a comprehensive clinical examination was performed. The main clinical features have been described in detail. SLEDAI-2K was used to assess the disease activity and its descriptors were documented as present or absent and each has a weighted score, with the total score ranged between 0 and 105 [10]. The Systemic Lupus International Collaborating Clinics/ACR Damage Index (SDI) was used to assess cumulative organ damage [18].

All the patients underwent laboratory tests required for assessment of disease activity and cumulative damage scores. The sera of the patients were screened for levels of complement components ( $\mathrm{C} 3$ and $\mathrm{C} 4)$, and positivity for antinuclear antibodies (ANA), double stranded deoxy ribonucleic acid (dsDNA) antibodies, anti-Smith (Sm) antibodies, anti-ribosomal phosphoprotein (anti-P) antibodies, antibodies to extractable nuclear antigens (antiRo and anti-La), and aPL antibodies.

\section{Assessment of headache and its impact}

The presence of headache was screened with an initial question about having headache during the past year. Headache sufferers were subjected to a detailed interview including the relevant neurological data and any data essential for the diagnosis and classification of headache. We used the ACR nomenclature and case definitions for NPSLE [11], where headache is diagnosed and classified according to the International Classification System for defining headache types [19]. This includes five types of primary headache: migraine, $\mathrm{TTH}$, cluster headache, headache from intracranial tension (ICT), and intractable non-specific headache. Entity "lupus headache" is one of the items in the SLEDAI-2K [10] and has been defined as a severe, disabling, persistent headache that is not responsive to narcotic analgesics.

Headache severity was measured using the visual analog scale (VAS) [20]. The results were recorded by making a handwritten mark on a line $10 \mathrm{~cm}$ long that represented a continuum between "no pain" and "worst possible pain."

The six-item Headache Impact Test (HIT-6) was used to measure the impact of headache on patients' daily life [21]. Items include pain, social functioning, role functioning, vitality, cognitive functioning, and psychological distress. The patient answers using one of the following five responses: "never," "rarely," "sometimes," "very often," or "always." The pooled responses yield a score of 36 to 78, and scores > 55 indicate moderate or severe headache disability.

\section{Brain imaging acquisition}

Brain MRI, MR angiography (MRA), and MR venography (MRV) were performed according to a standard imaging protocol. The protocol included T2-weighted turbo spin echo imaging in the axial plane, fluid-attenuated inversion recovery (FLAIR) sequence in the axial plane, T1weighted spin echo imaging in the axial and sagittal planes, diffusion-weighted images, apparent diffusion coefficient maps, three-dimensional time-of- flight MRA of the circle of Willis, and three-dimensional phase contrast MRV of the venous sinuses. This was performed on a General Electric optima $1.5 \mathrm{~T}$ clinical scanner (General Electric Medical Systems, MR450W) and an experienced radiologist, blinded to the patients' clinical data, checked all the images for any abnormalities. 
Lesions were categorized as white matter hyper intensities (WMH), ischemia, dural venous sinus thrombosis, small vessel disease and cerebral atrophy, and all visible abnormalities were recorded. WMH was defined as high signal intensity on T2-weighted images and FLAIR images. Ischemia was defined as increased diffusionweighted imaging (DWI) signal and reduced apparent diffusion coefficient (ADC) values in acute stage, high signal intensity on $\mathrm{T} 2$ and FLAIR weighted images in subacute stage and low signal intensity on T1 weighted images with high signal intensity on T2-weighted images in chronic stage. Dural venous sinus thrombosis was defined as filling defect in affected venous sinus on MRV sequence. Small vessel disease and atrophy was defined as subcortical and periventricular white matter lesions on T2-weighted sequences with enlarged cerebrospinal fluid spaces for a patient of their given age [14, 22, 23].

\section{Statistical analysis}

The collected data were tabulated and analyzed using SPSS version 16 software (Spss, Inc., Chicago, ILL Company). Qualitative data were presented as number and percentages, using chi-square $(\chi 2)$ test and Fisher's exact test (FET) for their analysis. Continuous data were tested for normality using Shapiro-Wilk test, assuming normality at $P>0.05$. They were expressed as mean \pm standard deviation if normally distributed or median, IQR, and range if not. Data Differences between 2 groups were tested using Mann-Whitney $U$ test (MWU) for nonparametric variables. Non-parametric correlations were assessed by Spearman's correlation coefficient (rho). ROC curve was constructed to detect cutoff values of the studied parameters with optimum sensitivity and specificity. Finally, logistic regression analysis was run to detect the significant predictors of headache among SLE patients. $P \leq 0.05$ was considered significant.

\section{Results}

\section{Demographics and headache characteristics}

A total of 57 patients with SLE were recruited, including 52 females $(91.2 \%)$ and 5 males $(8.8 \%)$ with a mean age of $38.7 \pm 9.7$ years. Of these 57 patients, 31 (54.4\%) had a primary headache. Among headache sufferers, migraine was the most common type recorded (48.4\%), followed by TTH (35.5\%), cluster headache (9.7\%), and finally both ICT headache and non-specific intractable headache (3.2\%). None of the patients met the SLEDAI$2 \mathrm{~K}$ criteria for lupus headache and none had more than one type of headache at the same time either. A Hit-6 score > 55 was found in $45.2 \%$ of the headache sufferers (14/31 patients). Headache characteristics and impact are described in table 1.
Table 1 Headache characteristics of SLE patients

\begin{tabular}{ll}
\hline Variable & Patients with headache $(\mathbf{n o}=\mathbf{3 1})$ \\
\hline Type of headache, no (\%) & $15(48.4)$ \\
Migraine & $11(35.5)$ \\
TTH & $3(9.7)$ \\
Cluster headache & $1(3.2)$ \\
ICT headache & $1(3.2)$ \\
Intractable headache & $6.0(4-7),[3-9]$ \\
VAS for headache severity & \\
Median (IQR), [range] & $52.0(46-66),[36-78]$ \\
HIT-6 for headache impact \\
Median (IQR), [Range]
\end{tabular}

$\pi H$ tension-type headache, ICT intra-cranial tension, VAS visual analog scale, IOR inter-quartile range, HIT-6 the six-item headache impact test

\section{Headache and SLE-related variables}

In order to investigate the relationship between headache and disease-related variables, SLE patients were divided into 2 groups: 31 SLE patients with headache (headache group) and 26 patients without headache (non-headache group) (Table 2). The two groups were comparable with respect to age, sex, and disease duration $(P>0.05)$. Patients with headache had a higher prevalence of musculoskeletal features $(P=0.008)$ and neuropsychiatric events $(P=0.02)$. The most common neuropsychiatric events in our patients were seizure, psychosis, and lastly cerebrovascular syndrome. Headache was not included as a neuropsychiatric event as none of our patients had a headache that met the criteria for a lupus headache. Apart from the significantly predominant aPL antibodies in the headache group (45.2\% in headache group vs $15.4 \%$ in non-headache group, $p=$ 0.016), the immunological data were comparable in both groups. Furthermore, headache sufferer had a higher SLEDAI-2K score $(p=0.016)$ and were more often treated with corticosteroids $(p=0.03)$.

Headache severity (VAS) and impact (HIT-6) were correlated with SLEDAI-2K $(P=0.019$ and $P<0.001$, respectively) and were also correlated with each other $(P=$ 0.006). Whereas only headache impact correlated with SDI $(P=0.024)$ (Table 3$)$.

Variables found to be significantly associated with headache (musculoskeletal and neuropsychiatric manifestations, SLEDAI-2K score, aPL antibodies, and corticosteroid therapy) were entered the multivariable binary logistic regression analysis to detect the significant predictors (Table 4). The presence of musculoskeletal features, aPL antibody positivity, and SLEDAI-2K score $\geq 13.5$ were identified as predictors of primary headache among SLE patients. This cutoff value $(\geq 13.5)$ was determined by the receiver operating characteristic (ROC) curve with a sensitivity $=71 \%$, a specificity $=$ $65.4 \%$, area under the curve (AUC $=0.685$ ) and $95 \%$ 
Table 2 Demographics, disease-related variables, and current medications in the headache and non-headache groups

\begin{tabular}{|c|c|c|c|}
\hline Variable & $\begin{array}{l}\text { Headache group } \\
(\text { no }=31)\end{array}$ & $\begin{array}{l}\text { Non-headache } \\
\text { group (no = 26) }\end{array}$ & $P$ \\
\hline $\begin{array}{l}\text { Age (years), mean } \pm \text { SD } \\
\text { [Range] }\end{array}$ & $\begin{array}{l}39.9 \pm 10.0 \\
{[18-59]}\end{array}$ & $\begin{array}{l}37.3 \pm 9.3 \\
{[18-56]}\end{array}$ & 0.33 \\
\hline Sex (female/male) & $(29 / 2)$ & $(23 / 3)$ & 0.65 \\
\hline $\begin{array}{l}\text { Disease duration (years) } \\
\text { Median (IQR),[range] }\end{array}$ & $\begin{array}{l}6.0(4-10) \\
{[0.5-20]}\end{array}$ & $\begin{array}{l}4.0(3-7.3) \\
{[0.5-13]}\end{array}$ & 0.12 \\
\hline \multicolumn{4}{|c|}{ Clinical manifestations, no (\%) } \\
\hline Constitutional & $9(29.0 \%)$ & $5(19.2 \%)$ & 0.39 \\
\hline Mucocutaneus & $17(54.8 \%)$ & 14(53.8\%) & 0.93 \\
\hline Musculoskeletal & 30 (96.8\%) & 18(69.2\%) & $0.008^{*}$ \\
\hline Serositis & $7(22.6 \%)$ & $6(23.1 \%)$ & 0.97 \\
\hline Renal & $8(25.8 \%)$ & $8(30.8 \%)$ & 0.68 \\
\hline Vasculitis & $9(29.0 \%)$ & $8(30.8 \%)$ & 0.88 \\
\hline Hematological & $11(35.5 \%)$ & 10(38.5\%) & 0.81 \\
\hline Neuropsychiatric & $12(38.7 \%)$ & $3(11.5 \%)$ & $0.02^{*}$ \\
\hline \multicolumn{4}{|c|}{ Immunological characteristics, no (\%) } \\
\hline ANA & $26(83.9 \%)$ & $24(92.3 \%)$ & 0.43 \\
\hline Anti-dsDNA & $22(71.0 \%)$ & $17(65.4 \%)$ & 0.65 \\
\hline Anti-Sm & $7(22.6 \%)$ & $7(26.9 \%)$ & 0.50 \\
\hline Anti-Ro & $9(29.0 \%)$ & $10(38.5 \% 0$ & 0.45 \\
\hline Anti-La & $6(19.4 \%)$ & $5(19.2 \% 0$ & 1.0 \\
\hline $\mathrm{aPL}$ & $14(45.2 \%)$ & $4(15.4 \% 0$ & $0.016^{*}$ \\
\hline Anti-P & $2(6.5 \%)$ & $1(3.8 \% 0$ & 1.0 \\
\hline Hypocomplementemia & $12(38.7 \%)$ & $9(34.6 \% 0$ & 0.75 \\
\hline \multicolumn{4}{|l|}{ SLEDAI-2K } \\
\hline $\begin{array}{l}\text { Median (IQR) } \\
\text { [range] }\end{array}$ & $\begin{array}{l}17.0(10-25) \\
{[6-38]}\end{array}$ & $\begin{array}{l}12.0(6.7-17.2) \\
{[4-29]}\end{array}$ & $0.016^{*}$ \\
\hline \multicolumn{4}{|l|}{ SDI } \\
\hline $\begin{array}{l}\text { Median (IQR) } \\
\text { [range] }\end{array}$ & $\begin{array}{l}2.0(1-3) \\
{[0-8]}\end{array}$ & $\begin{array}{l}2.0(0.8-2.3) \\
{[0-7]}\end{array}$ & $<0.55$ \\
\hline \multicolumn{4}{|l|}{ Current medications, $n$ (\%) } \\
\hline Glucocorticoids & $23(74.2 \%)$ & $12(46.2 \%)$ & $0.03^{*}$ \\
\hline Antimalarial & $22(71.0 \%)$ & $20(76.9 \%)$ & 0.61 \\
\hline AZA/MMF/MTX/CsA & $24(77.4 \%)$ & 19 (73.1\%) & 0.70 \\
\hline Belimumab & $3(9.7 \% 0$ & $3(11.5 \%)$ & 1.0 \\
\hline Rituximab & $5(16.1 \%)$ & $2(7.7 \%)$ & 1.0 \\
\hline Anti-platelet & $9(29.0 \%)$ & $9(34.6 \%)$ & 0.65 \\
\hline Anti-coagulant & $2(6.5 \%)$ & $1(3.8 \%)$ & 1.0 \\
\hline
\end{tabular}

SD Standard deviation, IQR Inter-quartile range, VAS Visual analog scale, ANA Anti-nuclear antibodies, dsDNA Double-stranded DNA antibodies, Sm AntiSmith antibodies, Anti-Ro and Anti-La Antibodies to extractable nuclear antigens, aPL Anti-phospholipid antibodies, Anti-P Anti-ribosomal phosphoprotein, SLEDAI-2K Systemic lupus erythematosus disease activity index, SDI Systemic Lupus International Collaborating Clinics/American College of Rheumatology (SLICC/ACR) Damage Index, AZA Azathioprine, MMF Mycophenolate mofetil, MTX Methotrexate, CSA Cyclosporin A, *P $\leq$ 0.05 : significant
Table 3 Correlation of headache severity and impact with selected disease related variables in the headache group

\begin{tabular}{llllll}
\hline Variable & \multicolumn{2}{l}{ Severity score (VAS) } & & \multicolumn{2}{l}{ Impact score (HIT-6) } \\
\cline { 2 - 3 } & $\boldsymbol{r}$ & $\boldsymbol{P}$ & & $\boldsymbol{r}$ & $\boldsymbol{P}$ \\
\hline Age & 0.156 & 0.403 & & 0.263 & 0.15 \\
Disease duration & 0.10 & 0.59 & & 0.195 & 0.29 \\
SLEDAI-2K & 0.418 & $0.019^{*}$ & & 0.705 & $<0.001^{*}$ \\
SDI & 0.284 & 0.12 & & 0.405 & $0.024^{*}$ \\
VAS & - & - & & 0.481 & $0.006^{*}$ \\
HIT-6 & 0.481 & $0.006^{*}$ & & - & - \\
\hline
\end{tabular}

VAS Visual analog scale, HIT-6 the six-item headache impact test, SLEDAI-2K Systemic lupus erythematosus disease activity index, SDI Systemic Lupus International Collaborating Clinics/American College of Rheumatology (SLICC/ ACR) Damage Index, ${ }^{*} P \leq 0.05$ significant

confidence interval $(\mathrm{CI})=0.55-0.82$. Interestingly, no significant association could be observed with the presence of neuropsychiatric manifestations.

\section{Imaging characteristics}

MRI brain was normal in 23/31 of patients presenting with headache $(74.2 \%)$, while abnormalities were detected in the remaining 8 patients (25.8\%). MRI abnormalities consisted of WMH in $5 / 31$ (16.1\%) and ischemia in $3 / 31(9.7 \%)$ of all headache sufferers. Of the five patients who had white matter changes on the MRI, two patients had TTH, one had migraine, one had ICT, and one had intractable headache. On the other hand, 3 patients had ischemic lesions, 2 of whom were migraine patients, and 1 patient had TTH. Of particular note, all patients with cluster headache $(n=3)$ had normal MRI (Fig. 1a, b).

Upon further analysis by comparing patients with normal and abnormal MRI findings regarding SLE (SLEDAI-2K and SDI) and headache (VAS and HIT-6) related variables, SDI was the only significantly higher score $(p=0.002)$ in headache patients with MRI abnormalities (data not shown). Moreover, ROC curve analysis showed that $\mathrm{SDI} \geq 2.5$ can significantly predict MRI changes in SLE patients with headache with $75 \%$

Table 4 Binary logistic regression analysis for the predictors of headache among SLE patients

\begin{tabular}{lllll}
\hline Variable & \multicolumn{4}{l}{ Multivariate logistic regression } \\
\cline { 2 - 5 } & $\boldsymbol{\beta}$ & Adjusted OR & $\mathbf{9 5 \%} \mathrm{Cl}$ & $\boldsymbol{P}$ \\
\hline SLEDAI-2K $\geq 13.5$ & 1.47 & 4.3 & $1.04-18.2$ & $0.044^{*}$ \\
Musculoskeletal manifestation $\mathrm{S}$ & 2.2 & 9.1 & $1.7-34.5$ & $0.017^{*}$ \\
Neuropsychiatric manifestations & 0.79 & 2.19 & $0.43-11.2$ & 0.34 \\
aPL Abs & 1.65 & 5.2 & $1.2-23.7$ & $0.032^{*}$ \\
Corticosteroids & 0.72 & 1.98 & $0.39-13.8$ & 0.43 \\
\hline OR Odd ratio, CI Confidence interval, SLEDAl-2K Systemic lupus erythematosus \\
disease activity index, $a P L$ Anti-phospholipid antibodies, * $P \leq 0.05$ significant
\end{tabular}


(a)

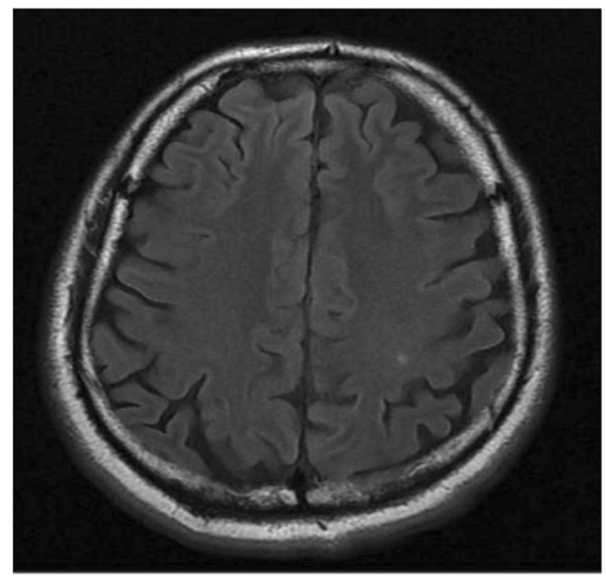

(b)

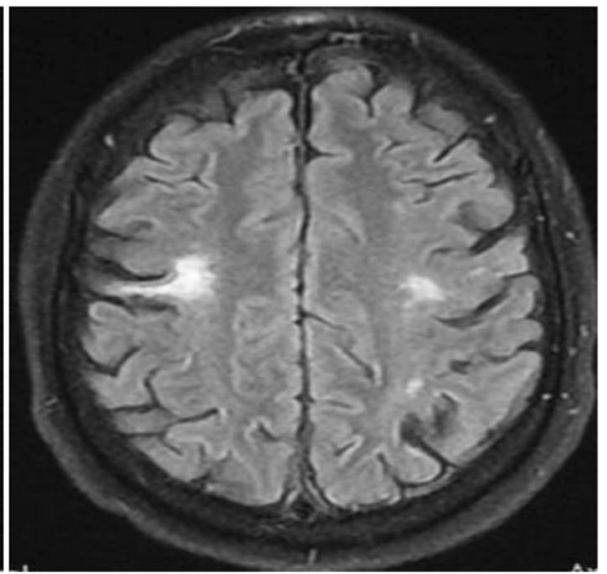

Fig. 1 a Axial FIAIR brain MRI exhibits non-specific hypertense white mater lesion in the left parietal region. b Axial FIAIR brain MRI exhibits hyperintensity lesions in both frontal subcortical white matter regions suggesting subacute infarcts. FIAIR, fluid-attenuated inversion recovery; MRI, magnetic resonance imaging

sensitivity, 82.6\% specificity, 60\% PPV, 90.5\% NPV; AUC $(95 \%$ CI $)=0.864$ (0.74-0.99) (Fig. 2).

\section{Discussion}

To date, no distinct pathogenetic mechanism for SLErelated headache has been demonstrated and relating headache directly with SLE is a challenge in the absence of diagnostic evidence. Furthermore, inclusion of headache as a neurological manifestation of SLE without restriction could overestimate NPSLE prevalence posing a risk of unnecessary aggressive therapies.

In our cohort, $54.4 \%$ of patients had a primary headache, which is in line with previously accumulated data showing a highly variable prevalence of headache in SLE patients with a range of 24 to $72 \%$ [6]. This wide range of prevalence is likely due to methodological heterogeneity including the different inclusion criteria applied in patients' selection and the lack of standardized definitions of headache. Although TTH is the most common primary headache in the general population, it has been reported that migraine is more prevalent in SLE patients compared to controls $[5,7]$. In agreement with these results, migraine was the most frequent type demonstrated in our patients. The exact prevalence of migraine in SLE is unknown, but a prevalence of $31-45 \%$ has been reported [24], which is similar to our results (48.4\%). It is not clear why migraine is more prevalent in SLE patients. An imbalance in neuronal excitability affecting multiple brain regions characterizes migraine disorder [25]. One possible cause of neuronal imbalance is the dysfunction of glial cells and astrocytes that can modulate neuronal excitability and might become activated in SLE patients [26]. However, a higher prevalence of TTH has been reported in SLE patients by some studies [1,
27], while others $[28,29]$ have observed an equal prevalence of migraine and TTH.

Although it may be defined as a migraine, other features such as being persistent, intractable, and unresponsive to narcotics must be fulfilled to identify a lupus headache [10]. Not surprisingly, no such type of headache was identified among our patients. In a metaanalysis by Mitsikostas et al. [7], insufficient evidence was found to support a distinctive entity of headache related to SLE. Furthermore, only 26 patients were classified as having lupus headache out of the 1732 SLE patients enrolled in a large prospective study [5]. Some authors [30] have questioned the validity of the inclusion of lupus headache in the SLEDAI-2K score, inquiring about the exact definition of the word "persistent." Moreover, response to analgesia is not a component of International Headache Society (IHS) definitions and narcotic use is not generally recommended for migraine treatment. Whether or not this type of headache actually exists is a matter of particular debate with the lack of evidence to support a specific pathogenetic mechanism in SLE.

According to our results, overall disease activity was significantly correlated with headache severity and impact, and a cut-off value of SLEDAI-2K score $\geq 13.5$ was determined to predict headache in SLE patients. Furthermore, musculoskeletal and neuropsychiatric manifestations were prevalent among headache sufferers. In line with our findings, Amit et al. [31] found a significant association between the occurrence of severe and prolonged headache, the history of neuropsychiatric manifestations, and the presence of more active disease in SLE patients. An additional association with severity of musculoskeletal, mucocutaneous, and constitutional 


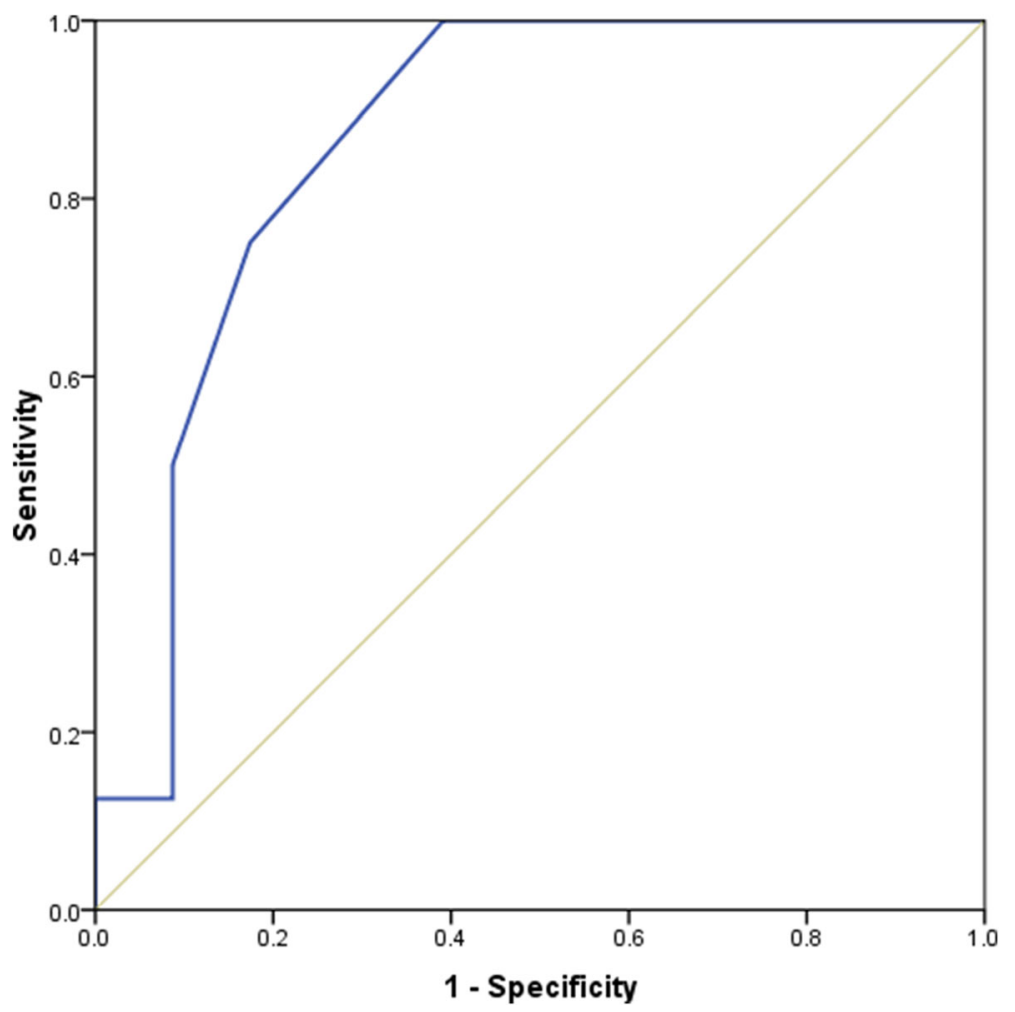

Fig. 2 ROC curve for the performance SDI in prediction of MRI changes. ROC curve analysis showed that SDI $\geq 2.5$ can significantly predict MRI changes in SLE patients with headache with 75\% sensitivity, 82.6\% specificity, 60\% PPV, and 90.5\% NPV; AUC (95\%Cl) = 0.864 (0.74-0.99). SDI, SLE International Collaborating Clinics/American College of Rheumatology Damage Index; MRI, magnetic resonance imaging; PPV, positive predictive value; NPV, negative predictive value; AUC, area under the ROC curve

features was demonstrated in the same study [31]. Raynaud's phenomenon has also been linked to the occurrence of headaches in SLE patients, especially migraines [32]. Conversely, in another study, the presence or type of headache was not associated with specific clinical manifestations or disease activity in SLE patients [33]. The somewhat surprising finding was that neuropsychiatric features were not among the factors that predict headache, despite their increased frequency among headache sufferers. However, Mitsikostas et al. [7] did not report any consistent association between neuropsychiatric features and any type of headache in adult SLE patients in their meta-analysis. Moreover, migraine was not a predictive factor for the development of other neuropsychiatric manifestations such as seizures or psychosis [34].

The question of whether headache in SLE patients represents CNS involvement or overall disease activity has been addressed. Although, there is no characteristic pathogenetic mechanism for the headache associated with SLE, circulating cytokines, and anti-phospholipid and anti-neuronal antibodies have been implicated as potential agents [1]. Like other authors [29], it was noted that headache coexisted with aPL-positive antibody in SLE patients; however, others [5, 35] did not confirm this association. Anti-phospholipid antibody positivity has been linked to non-thrombotic NPSLE syndromes, such as seizures and cognitive deficits, indicating that pathogenetic role of these antibodies exceed their prothrombotic effect [36]. However, our findings do not support the hypothetical role of anti-P antibodies in SLE-related headache, consistent with those of others [37].

In approximately $74 \%$ of our patients, no brain MRI abnormalities were found. These data are consistent with previous studies in SLE patients, as no significant association was reported between cerebral lesions and headache characteristics, including its types $\left[\begin{array}{ll}1,38 & 3\end{array}\right.$. Furthermore, Sarbu et al. [39] has not reported any major brain injuries such as large vessel disease or inflammatory-like lesions in SLE patients with headache. The absence of abnormalities in the majority of patients could be attributed to limitations of conventional MRI. Common brain MRI abnormalities detected in patients with NPSLE include WMH, brain atrophy, and infarction [40]. In accordance with previous reports [1], WMH was the most common MRI abnormality detected in SLE patients with headache. Despite its low specificity, WMH has been observed in up to $80 \%$ of NPSLE 
patients [39] and is typically characterized by numerous small-sized punctate lesions found in the periventricular and subcortical regions [14]. The role of white matter involvement in NPSLE is unclear; it has been shown to be present in patients with active NPSLE, inactive NPSLE [41], or SLE without overt neuropsychiatric manifestations as well as advanced aging [42].

In our study, MRI abnormalities have been shown to be associated with cumulative organ damage in line with other studies that have found an association between the cumulative damage of SLE and the time of disease progression with white matter lesions [43, 44]. Abda et al. [45] demonstrated MRI abnormalities in older NPSLE patients with longer disease duration. Additional associations have been reported between WMH and cognitive dysfunction [39, 43, 46], cerebrovascular disease [43], low complement (CH50) level [39], and aPL antibodies [46].

Consistent with previous data [37], the incidence of headache in SLE patients was associated with an impact of quality of life. Approximately $45 \%$ of headache sufferers had moderate to severe disability, which was found to be associated with headache severity. Hanly et al. [5] observed a significant decrease in quality of life associated with the presence of headache in SLE patients regardless of its etiology, with a significant improvement simultaneously with headache resolution reflecting its reversible nature.

This study has some limitations. First, the crosssectional design may have limited the ability to assess the effects of different treatment regimens on headache and its outcome. Second, MRI scans were not performed on patients without headache, and one scan was performed to each patient with headache using standardized conventional MRI protocols, but this reflects what is offered to patients in routine practice. Finally, our study did not include age- and gender-matched healthy controls; however, our overall goal was to study headache in SLE patients in relation to disease related parameters.

\section{Conclusions}

Primary headache, especially migraine, is a common feature of patients with SLE, and its presence is associated with an increased burden on life. Our findings neither support the existence of lupus headache (as defined by SLEDAI-2K) as a separate entity nor as a sign of CNS involvement; however, musculoskeletal features, aPL positivity, and overall disease activity appear to predict primary headache in SLE patients. Multicenter prospective studies using morphological and functional neuroimaging techniques to provide insights into the pathogenic mechanisms of headache in SLE are warranted.

\section{Abbreviations}

SLE: Systemic lupus erythematosus; SLEDAI-2K: SLE Disease Activity Index SDI: SLE International Collaborating Clinics/American college of
Rheumatology Damage Index; AZA: Azathioprine; MMF: Mycophenolate mofetil; MTX: Methotrexate; CsA: Cyclosporin; IHS: International Headache Society; VAS: Visual analog scale; HIT-6: Six-item headache impact test; MRI: Magnetic resonance imaging; WMH: White-matter hyperintensities; aPL: Anti-phospholipid antibodies; NPSLE: Neuropsychiatric SLE; TTH: Tensiontype headache; ACR: American College of Rheumatology; ICT: Intracranial tension; C3 and C4: Complement components; ANA: Anti-nuclear antibodies; dsDNA: Double-stranded deoxy ribonucleic acid antibodies; Sm: Anti-Smith antibodies; Anti-P: Anti-ribosomal phosphoprotein antibodies; Anti-Ro and anti La: Antibodies to extractable nuclear antigens; MRA: MR angiography; MRV: MR venography; FLAIR: Fluid-attenuated inversion recovery;

DWI: Diffusion-weighted imaging; ADC: Apparent diffusion coefficient; X2: Chi-square test; FET: Fisher's exact test; MWU: Mann-Whitney $U$ test; IHS: International Headache Society

\section{Acknowledgements}

The authors would like to thank all participants in the study for their participation.

\section{Authors' contributions}

All authors participated in the study design. G.E. made primary contributions from inception of idea, data acquisition, analysis and interpretation, and preparing of the final manuscript. A.A. made notable contributions in study design, analysis, and interpretation of data. D.Y. was responsible of neurological examination, analysis of headaches, and interpretation of data. H.E. made major contributions in radiological aspect and interpretation of MRI. E.B. made primary contributions in analysis and interpretation of data and preparing of the final manuscript. All authors read, revised, and approved the final manuscript.

\section{Funding}

This research did not receive any specific grant from funding agencies in the public, commercial, or not-for-profit sectors.

\section{Availability of data and materials}

All are available.

\section{Declarations}

Ethics approval and consent to participate

The Permanent Committee for the Coordination of Medical and Health Research at the Kuwaiti Ministry of Health approved this research on 11 February 2020 (reference number: 2020/12624). This research was conducted according to the standard of the Declaration of Helsinki and all participants signed written informed consent.

Consent for publication

Not applicable.

\section{Competing interests}

The authors declare that they have no competing interests.

\section{Author details}

${ }^{1}$ Rheumatology and Rehabilitation Department, Benha Faculty of Medicine, Benha, Egypt. ${ }^{2}$ Rheumatology Unit, Internal Medicine Department, Al Adan Hospital, Al Ahmadi, Kuwait. ${ }^{3}$ Neurology Department, Cairo Faculty of Medicine, Cairo, Egypt. ${ }^{4}$ Neurology Department, Ibn Sina Hospital, Kuwait City, Kuwait. ${ }^{5}$ Radiology Department, Al Adan Hospital, Al Ahmadi, Kuwait.

Received: 14 June 2021 Accepted: 26 July 2021

Published online: 15 September 2021

\section{References}

1. Bicakci S, Ozbek S, Bicakci K, Aslan K, Kara B, Sarica Y (2008) Recurrent headache and MRI findings in systemic lupus erythematosus. J Natl Med Assoc 100(3):323-326. https://doi.org/10.1016/S0027-9684(15)31245-1

2. Papadaki E, Fanouriakis A, Kavroulakis E, Karageorgou D, Sidiropoulos P, Bertsias G, Simos P, Boumpas DT (2018) Neuropsychiatric lupus or not? Cerebral hypoperfusion by perfusion-weighted MRI in normal-appearing white matter in primary neuropsychiatric lupus erythematosus. Ann Rheum Dis 77(3):441-448. https://doi.org/10.1136/annrheumdis-2017-212285 
3. Son CN, Kim SH, Chang HW, Kim JM (2016) A neurometabolite study of chronic daily headache in patients with systemic lupus erythematosus using magnetic resonance spectroscopy: comparison with fibromyalgia patients and healthy controls. Korean J Intern Med 31(6):1171-1177. https://doi.org/1 0.3904/kjim.2015.196

4. Goh KJ, Hentzen A, Alders EE, Tan CT, Hoh MC (1997) Headache and systemic lupus erythematosus: is there an entity of "lupus headache"? Neurol J Southeast Asia 2:51-56

5. Hanly JG, Urowitz MB, O'Keeffe AG, Gordon C, Bae SC, Sanchez-Guerrero J, Romero-Diaz J, Clarke AE, Bernatsky S, Wallace DJ, Ginzler EM, Isenberg DA, Rahman A, Merrill JT, Petri M, Fortin PR, Gladman DD, Fessler BJ, Alarcón GS, Bruce IN, Dooley MA, Steinsson K, Khamashta MA, Ramsey-Goldman R, Manzi S, Sturfelt GK, Nived O, Zoma AA, van Vollenhoven RF, Ramos-Casals M, Aranow C, Mackay M, Ruiz-Irastorza G, Kalunian KC, Lim SS, Inanc M, Kamen DL, Peschken CA, Jacobsen S, Theriault C, Thompson K, Farewell V (2013) Headache in systemic lupus erythematosus: results from a prospective, international inception cohort study. Arthritis Rheum 65(11): 2887-2897. https://doi.org/10.1002/art.38106

6. Hanly JG (2011) The nervous system and lupus. In: Lahita RG, Tsokos G, Buyon J, Koike T (eds) Systemic lupus erythematosus, 5th edn. Elsevier, Philadelphia, pp 727-746. https:/doi.org/10.1016/B978-0-12-374994-9.10040-3

7. Mitsikostas DD, Sfikakis PP, Goadsby PJ (2004) A meta-analysis for headache in systemic lupus erythematosus: the evidence and the myth. Brain. 127(Pt 5):1200-1209. https://doi.org/10.1093/brain/awh146

8. Schreiber K, Jacobsen S (2016) Neuropsychiatric systemic lupus erythematosus. In: Roccatello D, Emmi L (eds) Connective Tissue Disease, 1st edn. Springer International Publishing, Switzerland, pp 113-131

9. Kozora E, Erkan D, West SG, Filley CM, Zhang L, Ramon G, Duggan E, Lockshin MD (2013) Site differences in mild cognitive dysfunction (MCD) among patients with systemic lupus erythematosus (SLE). Lupus 22(1):7380. https://doi.org/10.1177/0961203312468963

10. Gladman DD, Ibañez D, Urowitz MB (2002) Systemic lupus erythematosus disease activity index 2000. J Rheumatol 29(2):288-291

11. Liang MH, Corzillius M, Bae SC, Lew RA, Fortin PR, Gordon C, et al. The American College of Rheumatology nomenclature and case definitions for neuropsychiatric lupus syndromes. Arthritis and rheumatism 1999:42(4):599-608.

12. Whitelaw DA, Spangenberg J (2009) An investigation in the possible effect of chronic headache on neuropsychological function in aCL-negative patients with SLE. Lupus 18(7):613-617. https://doi.org/10.1177/09612033 08101282

13. Uluduz D, Tavsanli ME, Uygunoğlu U, Saip S, Kasapcopur O, Ozge A, Temel GO (2014) Primary headaches in pediatric patients with chronic rheumatic disease. Brain Dev 36(10):884-891. https://doi.org/10.1016/j.braindev.2014.01.009

14. Jeong HW, Her M, Bae JS, Kim SK, Lee SW, Kim HK, Kim D, Park N, Chung WT, Lee SY, Choe JY, Kim IJ (2015) Brain MRI in neuropsychiatric lupus: associations with the 1999 ACR case definitions. Rheumatol Int 35(5):861869. https://doi.org/10.1007/s00296-014-3150-8

15. Karassa FB, loannidis JP, Boki KA, Touloumi G, Argyropoulou MI, Strigaris KA et al (2000) Predictors of clinical outcome and radiologic progression in patients with neuropsychiatric manifestations of systemic lupus erythematosus. Am J Med 109(8):628-634. https://doi.org/10.1016/S00029343(00)00603-3

16. Hochberg MC (1997) Updating the American College of Rheumatology revised criteria for the classification of systemic lupus erythematosus. Arthritis Rheum 40(9):1725. https://doi.org/10.1002/art.1780400928

17. Tan EM, Cohen AS, Fries JF, Masi AT, Mcshane DJ, Rothfield NF, Schaller JG, Talal N, Winchester RJ (1982) The 1982 revised criteria for the classification of systemic lupus erythematosus. Arthritis Rheum. 25(11):1271-1277. https:// doi.org/10.1002/art.178025110

18. Gladman DD, Goldsmith CH, Urowitz MB, Bacon P, Fortin P, Ginzler E, Gordon C, Hanly JG, Isenberg DA, Petri M, Nived O, Snaith M, Sturfelt G (2000) The Systemic Lupus International Collaborating Clinics/American College of Rheumatology (SLICC/ACR) Damage Index for Systemic Lupus Erythematosus International Comparison. J Rheumatol 27(2):373-376

19. Magnusson JE, Becker WJ. Classification and diagnostic criteria for headache disorders, cranial neuralgia and facial pain. Headache Classification Committee of the International Headache Society. Cephalalgia. 1998;8(Suppl 7):1-96.

20. Aicher B, Peil H, Peil B, Diener HC (2012) Pain measurement: visual analogue scale (VAS) and verbal rating scale (VRS) in clinical trials with OTC analgesics in headache. Cephalalgia 32(3):185-197. https://doi.org/10.1177/03331 024111430856
21. Kosinski M, Bayliss MS, Bjorner JB, Ware JE, Garber WH, Batenhorst A et al (2003) A six-item short-form survey for measuring headache impact: the HIT-6. Qual Life Res 12(8):963-974. https://doi.org/10.1023/A:1026119331193

22. Lalani TA, Kanne JP, Hatfield GA, Chen P (2004) Imaging findings in systemic lupus erythematosus. Radiographics 2(4):1069-1086

23. Goh YP, Naidoo P, Ngian GS (2013) Imaging of systemic lupus erythematosus. Part I: CNS, cardiovascular, and thoracic manifestations. Clin Radiol 68(2):181-191. https://doi.org/10.1016/j.crad.2012.06.110

24. Appenzeller S, Costallat LT (2004) Clinical implications of migraine in systemic lupus erythematosus: relation to cumulative organ damage. Cephalalgia 24(12):1024-1030. https://doi.org/10.1111/j.1468-2982.2004. 00785.x

25. Vecchia D, Pietrobon D (2012) Migraine: a disorder of brain excitatoryinhibitory balance? Trends Neurosci 35(8):507-520. https://doi.org/10.1016/j. tins.2012.04.007

26. Trysberg E, Nylen K, Rosengren LE, Tarkowski A (2003) Neuronal and astrocytic damage in systemic lupus erythematosus patients with central nervous system involvement. Arthritis Rheum 48(10):2881-2887. https://doi. org/10.1002/art.11279

27. Badry R, Gamal RM (2015) Different types of headache in patients with systemic lupus erythematosus. Int J Neurosci 125(5):357-360. https://doi. org/10.3109/00207454.2014.951041

28. Markus HS, Hopkinson N (1992) Migraine and headache in systemic lupus erythematosus and their relationship with antibodies against phospholipids. J Neurol 239(1):39-42. https://doi.org/10.1007/BF00839210

29. Sanna G, Bertolaccini ML, Cuadrado MJ, Laing H, Khamashta MA, Mathieu A, Hughes GR (2003) Neuropsychiatric manifestations in systemic lupus erythematosus: prevalence and association with antiphospholipid antibodies. J Rheumatol 30(5):985-992

30. Davey R, Bamford J, Emery P (2007) The validity of the inclusion of "lupus headache" in the Systemic Lupus Erythematosus Disease Activity Index. Arthritis Rheum 56(8):2812-2813. https://doi.org/10.1002/art.22798

31. Amit M, Molad Y, Levy O, Wysenbeek AJ (1999) Headache in systemic lupus erythematosus and its relation to other disease manifestations. Clin Exp Rheumatol 17(4):467-470

32. Lessa B, Santana A, Lima I, Almeida JM, Santiago M (2006) Prevalence and classification of headache in patients with systemic lupus erythematosus. Clin Rheumatol 25(6):850-853. https://doi.org/10.1007/s10067-005-0186-x

33. Katsiari CG, Vikelis M, Paraskevopoulou ES, Sfikakis PP, Mitsikostas DD (2011) Headache in systemic lupus erythematosus vs multiple sclerosis: a prospective comparative study. Headache 51(9):1398-1407. https://doi.org/1 0.1111/j.1526-4610.2011.01962.x

34. Sfikakis PP, Mitsikostas DD, Manoussakis MN, Foukaneli D, Moutsopoulos HM (1998) Headache in systemic lupus erythematosus: a controlled study. $\mathrm{Br} J$ Rheumatol 37(3):300-303. https://doi.org/10.1093/rheumatology/37.3.300

35. Tjensvoll AB, Harboe E, Gøransson LG, Beyer MK, Greve OJ, Herigstad A, Kvaløy JT, Omdal R (2011) Migraine is frequent in patients with systemic lupus erythematosus: a case-control study. Cephalalgia 31(4):401-408. https://doi.org/10.1177/0333102410372428

36. Schwartz N, Stock AD, Putterman C (2019) Neuropsychiatric lupus: new mechanistic insights and future treatment directions. Nat Rev Rheumatol 15(3):137-152. https://doi.org/10.1038/s41584-018-0156-8

37. Tjensvoll AB, Gøransson LG, Harboe E, Kvaløy JT, Omdal R (2014) High headache-related disability in patients with systemic lupus erythematosus and primary Sjögren's syndrome. Eur J Neurol 21(8):1124-1130. https://doi. org/10.1111/ene.12447

38. Intiso D, Di Rienzo F, Rinaldi G, Zarrelli MM, Giannatempo GM, Crociani P et a (2006) Brain MRI white matter lesions in migraine patients: is there a relationship with antiphospholipid antibodies and coagulation parameters? Eur J Neurol 13(12):1364-1369. https://doi.org/10.1111/j.1468-1331.2006.01519.x

39. Sarbu N, Alobeidi F, Toledano P, Espinosa G, Giles I, Rahman A, Yousry T, Capurro S, Jäger R, Cervera R, Bargalló N (2015) Brain abnormalities in newly diagnosed neuropsychiatric lupus: systematic MRI approach and correlation with clinical and laboratory data in a large multicenter cohort. Autoimmun Rev 14(2):153-159. https://doi.org/10.1016/j.autrev.2014.11.00

40. Cuadrado MJ, Sanna G (2003) Headache and systemic lupus erythematosus. Lupus 12(12):943-946. https://doi.org/10.1191/0961203303lu5060a

41. Appenzeller S, Pike GB, Clarke AE (2008) Magnetic resonance imaging in the evaluation of central nervous system manifestations in systemic lupus erythematosus. Clin Rev Allergy Immunol 34(3):361-366. https://doi.org/10.1 007/s12016-007-8060-z 
42. Sanna G, Piga M, Terryberry JW, Peltz MT, Giagheddu S, Satta L, Ahmed A, Cauli A, Montaldo C, Passiu G, Peter JB, Shoenfeld Y, Mathieu A (2000) Central nervous system involvement in systemic lupus erythematosus: cerebral imaging and serological profile in patients with and without overt neuropsychiatric manifestations. Lupus 9(8):573-583. https://doi.org/10.11 91/096120300678828695

43. Ainiala H, Dastidar P, Loukkola J, Lehtimäki T, Korpela M, Peltola J, Hietaharju A (2005) Cerebral MRI abnormalities and their association with neuropsychiatric manifestations in SLE: a populationbased study. Scand J Rheumatol 34(5):376-382. https://doi.org/10.1080/03009740510026643

44. Appenzeller S, Bonilha L, Rio PA, Li LM, Costallat LT, Cendes F (2007) Longitudinal analysis of gray and white matter loss in patients with systemic lupus erythematosus. Neurolmage 34(2):694-701. https://doi.org/1 0.1016/j.neuroimage.2006.09.029

45. Abda EA, Selim ZI, Radwan ME, Mahmoud NM, Herdan OM, Mohamad KA et al (2013) Markers of acute neuropsychiatric systemic lupus erythematosus: a multidisciplinary evaluation. Rheumatol Int 33(5):12431253. https://doi.org/10.1007/s00296-012-2531-0

46. Appenzeller S, Vasconcelos Faria A, Li LM, Costallat LT, Cendes F (2008) Quantitative magnetic resonance imaging analyses and clinical significance of hyperintense white matter lesions in systemic lupus erythematosus patients. Ann Neurol 64(6):635-643. https://doi.org/10.1002/ana.21483

\section{Publisher's Note}

Springer Nature remains neutral with regard to jurisdictional claims in published maps and institutional affiliations.

\section{Submit your manuscript to a SpringerOpen ${ }^{\circ}$ journal and benefit from:}

- Convenient online submission

- Rigorous peer review

- Open access: articles freely available online

High visibility within the field

- Retaining the copyright to your article

Submit your next manuscript at $\boldsymbol{\nabla}$ springeropen.com 